\title{
Mental Health Situation and Strategic Suggestions of College Students in Hubei Province During the Epidemic Situation
}

\author{
Gaojun Han ${ }^{1, a}$, Ling Yan ${ }^{2, \text { b, }}$ and Zhengjun Wang ${ }^{2, c}$ \\ ${ }^{1}$ Wuhan Institute of Technology, Wuhan 430205, China \\ ${ }^{2}$ The College of Post and Telecommunication of Wuhan Institute of Technology, Wuhan 430205, China \\ Emai:a477826007@qq.com, b,*286355793@qq.com,"93349102@qq.com
}

\begin{abstract}
During the epidemic period, the long-term domestic life will apply some negative effects on the mental health status of college students who stay in the stage of adolescence. Aiming to this problem, firstly, the mental health statuses of college students in Hubei Province during the period have been analyzed. Then the characteristics of the mental health statuses have been summarized. Finally, according to the actual situation, in this paper, some coping strategies and suggestions of psychological crisis have been proposed.
\end{abstract}

Keywords: Epidemic period, Psychological crisis, Psychological education of college students.

\section{INTRODUCTION}

The COVID-19, as a public health event, attracts wide attention in the world, which causes a situational crisis. Regarding the provincial capital of Hubei province, the city of Wuhan, with numerous colleges and universities, has made a very important contribution to the epidemic situation and accompanied by great sacrifices.

Some studies indicate that the psychological crisis caused by post-epidemic psychological disorders widely exists in people. (Wen and Chen, 2019; Guo and Jiang, 2020)

The group panic caused by the extremely infectious and asymptomatic infection of the disease, is a great spiritual sharpening and challenge for the whole society. Especially for the college students of the post-90s and post-00 generations, because of their critical stage of self-integration.

Regarding the above mentioned problem, in this paper, firstly, the characteristics of mental health of college students in Hubei province have been discussed. Then, from the perspective of society, university, family and personal education, some strategies have been proposed to tackle with this issue.

\section{CHARACTERISTICS OF COLLEGE STUDENTS' MENTAL HEALTH IN HUBEI PROVINCE DURING THE EPIDEMIC}

Human fear or anxiety response is the adaptive response preserved in evolution. This response can be explained as a gradual development process, namely, a human individual will experience the relevant physical and mental reactions for $6-8$ weeks, then step into the psychological crisis, and gradually recover from the negative state finally.

However, due to the synergistic effect of individual quality and severity of the event, around $20 \%$ of people experience excessive stress responses, such as excessive panic, anxiety, insomnia, or stay in the negative state for more than a month

After facing the epidemic directly, the value identification of college students in Hubei province is becoming more rational; meanwhile, the overall psychological crisis situation still cannot be ignored. In this case, the mental health of them presents remarkable characteristics, which can be summarized as follow.

\subsection{The Emotion Present Significant Time Differences in Crisis Processes}

In the first stage of the epidemic, students showed lower negative emotions than students outside the 
province. However, in the second stage, the opposite situation appears, accompanying obvious traumatic behavior. This phenomenon can be owed to the "typhoon eye effect" in the early stage of the epidemic. Students in the disaster-prone areas are calmer than students in other areas, and students outside feel more nervous and afraid. As the epidemic continues, it showed a completely opposite situation according to the survey in February. The students in the province are under great pressure every day when the closure time extends within the foreseeable future, and their emotions, compared with students in other provinces, have an "exposure effect ", which showed a higher level of tension and fear.

\subsection{The Online Help-Seeking Consciousness Is Obvious}

Long home life can trigger a series of home-problems. But on the whole, the consciousness of seeking help of college students is more obvious than that of ordinary people. Students who have returned home from Wuhan bear the heavy pressure of public opinion, and the feeling of being discriminated, excluded and peeped is obvious.

\subsection{Electronics Dependency Caused by Too Long Online Time}

Hubei province is the last province to lift the ban after the epidemic control. College students generally spend their time on games and short-videos for long time. According to statistics (Zhang et al., 2020), during the Spring Festival, the top ten chess and board games in a day increased more than three times than daily, mobile game users grew by $30 \%$ over usual, daily usage time per person increased by $17.8 \%$, and King of Glory and Peace Elite users all grew by more than $30 \%$.

The data from "Yi Guan Qian Fan" show that the average daily usage length of Kwai and TikTok users has increased by nearly 100 million hours within 5 days of January 26-30 than before the festival (January 1-23). Although games and short-videos brought a few entertainment times to college students during the epidemic, they seriously affected the students' focus and thinking, and developed their dependence on electronic products.

\subsection{Significant Increase of Sudden Family Conflicts during Home-Life}

During the epidemic period, the economy stagnated in the province, and the loss or delay of the labor opportunities of migrant workers led to a sharp decline in the family income of many provincial residents and the increasing professional pressure. At the same time, with the lack of effective communication, family conflicts (Ye and Zhong, 2020). After the epidemic, the workload of consultants from the Hubei Family and Marriage Research Association (HFMRA) increased by about $60 \%$ from March to June. After the epidemic, the workload of counselors in the HFMRA increased by about $60 \%$ in March and June. The most affected are the children, especially the students. The problem of bad family mood is a great challenge to the mental health of college students, which may lead to students' closed self, low self-identity, depression or anxiety.

\subsection{Provincial Colleges Students Have High Emotional Sensitivity and Obvious Compulsion}

According to the survey data of Huazhong University of Science and Technology (Zhang et al., 2020), college students in the province are more concerned about their mental health, and on the duration of the COVID-19, the relevant statistics are shown in Table 1 .

Table 1. Statistics on the duration, frequency and state of concern of students browsing about the epidemic

\begin{tabular}{|c|c|c|}
\hline Item & Data / Status & Percentage \\
\hline \multirow{3}{*}{ Browse Time } & $1 \mathrm{~h}$ & $62.39 \%$ \\
\cline { 2 - 3 } & $2-3 \mathrm{~h}$ & $24.68 \%$ \\
\cline { 2 - 3 } & $4-6 \mathrm{~h}$ & $5.28 \%$ \\
\cline { 2 - 3 } Frequency & $6 \mathrm{~h} \mathrm{up}$ & $3.52 \%$ \\
\cline { 2 - 3 } & 5 times & $44.89 \%$ \\
\cline { 2 - 3 } State of concern & 10 times & $30.4 \%$ \\
\cline { 2 - 3 } & 15 times & $58.45 \%$ \\
\cline { 2 - 3 } & Fear of infection & $58.19 \%$ \\
& infection & $50.46 \%$ \\
\hline
\end{tabular}

As shown in Table 1, some students in the province pay too much attention to the information of the epidemic, which leads to depression, sadness, fatigue, mental retardation, learning difficulty to concentrate, and depression transmitted by others around them, which may lead to depression. In addition, the rest of the groups often suspect that they were not thoroughly disinfected, and repeatedly disinfected their own supplies and contact items. It seems the anancastia appears.

\subsection{Significant Improvement in the Sense of Responsibility and Cohesion of the Students}

Regarding the attitude of receiving epidemic information, the students were more objective and rational. Meanwhile, in the emotional management of the later stage of the epidemic, most students were more stable (One Spirit, 2020), and the statistical results are shown in Table 2. 
Table 2. Statistics on negative information and emotional status of college students in the province

\begin{tabular}{|c|c|c|}
\hline Item & Behavior / Status & Proportion \\
\hline \multirow{4}{*}{$\begin{array}{c}\text { Negative } \\
\text { information of } \\
\text { the epidemic }\end{array}$} & Information verification & $59.95 \%$ \\
\cline { 2 - 3 } & Follow the message alert & $33.79 \%$ \\
\cline { 2 - 3 } & $\begin{array}{c}\text { Forward the message } \\
\text { immediately }\end{array}$ & $3.94 \%$ \\
\hline \multirow{4}{*}{ Emotional state } & $\begin{array}{c}\text { Judgment and selective } \\
\text { forwarding }\end{array}$ & $64.6 \%$ \\
\cline { 2 - 3 } & Peace & $80.32 \%$ \\
\cline { 2 - 3 } & Anxiety & $29.91 \%$ \\
\cline { 2 - 3 } & Moved & $21.34 \%$ \\
\cline { 2 - 3 } & Tension & $21.27 \%$ \\
\hline
\end{tabular}

In terms of social responsibility contribution, the survey shows that during the period, the students were most worried about their families, and especially wanted to contribute their own abilities to help the society. In the social order, the students show an obvious sense of justice. The results of the reasons of the sadness and anger are shown in Table 3.

Table 3. Statistics on causes of sadness and anger

\begin{tabular}{|c|c|c|}
\hline $\begin{array}{c}\text { Emotional } \\
\text { state }\end{array}$ & Causes & Proportion \\
\hline \multirow{4}{*}{ sad } & Helpless medical staff & $66.03 \%$ \\
\cline { 2 - 3 } & Helpless patients & $59.31 \%$ \\
\cline { 2 - 3 } & Innocent masses of the & $59.75 \%$ \\
\cline { 2 - 3 } & Lack of protective materials & $54.5 \%$ \\
\hline \multirow{4}{*}{ anger } & Forcing up price & $74.33 \%$ \\
\cline { 2 - 3 } & Irresponsible rumors & $73.54 \%$ \\
\cline { 2 - 3 } & $\begin{array}{c}\text { Suspected infected person } \\
\text { escape from epidemic area }\end{array}$ & $62.03 \%$ \\
\cline { 2 - 3 } & Epidemic of concealment & $65.31 \%$ \\
\hline
\end{tabular}

\section{SUGGESTIONS}

(3.1) Established and perfected the service system for psychological crisis intervention. We will build a basic project for social and psychological services, and appropriately create an atmosphere of public opinion in preparing to return to work.

(3.2) Strengthening the construction and improvement of the social security system, including medical testing, psychological intervention, community construction, legal support and many other aspects (Yang et al.,2020).

(3.3) Increasing the investment in the employment of college students. Improved the relevant mechanism of higher talents remaining in the province, so that students can also become a new force in the economic development of the province.

(3.4) Encouraging the establishment of a more effective home-school linkage mechanism. In this linkage system, we enable parents and students to grow up together and establish an effective parent-child interaction system (Bai et al., 2020; Yan, 2020).

(3.5) Colleges need to emphasize the professionalism and standardization of psychological education, and to strengthen the psychological construction of students and teenagers from top to bottom, which is mean to start from primary school, to carry out mental health education with lifelong learning goals, further strengthen and deepen the mental health education work.

\section{CONCLUSION}

Regarding the above discussion, the mental health of college students in Hubei province have been changing but controllable. The emphasis to the professionalism and standardization of psychological education, and the more effective home-school linkage mechanism should be implement.

\section{REFERENCES}

[1] Wen Ying, Chen Jianxin (2019). Application of Psychological Evaluation in the Investigation of Mental Health of College Students-Survey of a Hubei University. Psychology Progress, 9 (6), 1088-1093.

[2] Guo Qingqing, Jiang Hao (2020). The Psychological Impact and Strategy of the COVID-19 Epidemic on Returning College Students. Frontier of Social Sciences, 9 (7): 1043-1050.

[3] Bai Shiqian, Guo Li, Fan Jingyi (2020). Investigation and Analysis of Children in Hubei under COVID-19. Psychological Progress, 10 (7), 1040-1046.

[4] Yang Shikang, Wang Chao, Yang Yong, Xie Keliang (2020). Falling Medical Students' Mental Health Status Analysis. Psychological Progress, 10 (9), 1357-1362.

[5] Ye Tong, Zhong Xiaochuan (2020). Investigation and research on the negative emotional life cycle of college students during the outbreak. Psychology Progress, 10 (7), 1015-1022.

[6] Yan Ling (2020). Research on the Strategy of Home-school Cooperation in Precision Support Work of Colleges Based on Psychological Quality of the Students. 6th Annual International Conference on Social Science and Contemporary Humanity Development.121-123.

[7] One Spirit (2020). Psychological and behavioral insight report of the mass epidemic. https://www.ydl.com/jingyan/10548.

[8] Zhang Yan, Lei Guanghui, Bian Yue Ran, Wang Guixiang, Huang Fei, Xie Si Miao, Zhang Jinyuan (2020). The Trend of Psychological Change and the Coping Measures of College Students during the COVID-19. https://www.sohu.com/a/375571571_608848. 